\title{
The Philosophy of Organization Strategy: Critical Area's for Successful Strategy
}

\author{
Kurai Mugwagwa (BPA) \\ MPA student at University of Lusaka, Post-graduate School, \\ P.O. Box, 36711 off Alick Nkhata Road, Mass Media, June 2019, Lusaka, Zambia
}

\begin{abstract}
This article explains how organizational strategy, environment and decisions are made by management of organizations to successfully achieve goals and objectives through building a sustainable competitive advantage by leveraging resources and capabilities. The writer is of the view that the aspect of strategy, environment and decisions in modern day organizations is critical to its long term survival. Through and through, organizations formulates and implement various kinds of strategies that help galvanize its capabilities for competitive advantage. The achievement of objectives and goals that increase trust and cohesion between management and stakeholders is as a result of engendering in a mix of successful formulated and implemented strategies. By using a content or discourse analysis technique through extensive exploration of various literatures concerned with strategy in the ambit of qualitative research methodology, this article has explored and discussed different key areas necessary for the success of any organizational strategy. The external environment and various decisions made in modern organization have also being expounded comprehensively. The study reveals that the key areas raised and discussed in this article are areas were organization strategy is made or broken.
\end{abstract}

Keywords: strategy, organization, environment, decisions

DOI: $10.7176 /$ PPAR/9-6-08

Publication date:June $30^{\text {th }} 2019$

\section{Introduction}

The term strategy as was postulated and espoused by (Thompson and Strickland: 2003) refers to "a managerial process consisting of a formed strategic vision, set of objectives, crafted and bundled together, implemented or in the process of being executed for the achievement of a goal". This definition captures two main elements that go to the heart of the field of strategic management. First, strategy of an organization entails three ongoing processes that management do; continuous analysis of the environment, continuous decision making, and endless action taking. That is strategy is concerned with the achievement of organizational goal aligned in the vision, mission, and strategic objectives) in the presence of an ever changing external environment. Secondly, the essence of strategy is to outperform competitors. Thus managers need to determine how a firm is to compete so that it can achieve competitive advantages that are sustainable over a lengthy period of time. However, over time corrective measures are instigated whatever there are necessary adjustments in the vision, mission, objectives, and structure or due to external pressures (Davis and Olson, 2008). On the one hand (Kotler: 1991, p: 234) argued that managers of successful organizations are "action-oriented strategic-thinkers and movers who make a habit of keeping an eye on customer needs, new opportunities and competitive positioning while controlling internal operations". These managers are aware of their responsibility to shape their organization's long term direction, formulate a coherent strategic action plan that will produce competitive advantage and long-term financial success, and orchestrate successful implementation of the chosen strategy (Bhide, 1994, p: 150-161). They are good strategists and entrepreneurs as well as good insightful leaders. Therefore, having a well-articulated and realized strategy in an organization such as universities, a church, in government or in a home is a key factor in achieving desired goals of that particular institution.

\section{Methodology}

In this article, a qualitative research methodology was adopted by way of embarking on extensive search and exploration of various literatures relating to organization strategy using content analysis as a research technique. Baxter and Jack (2008) posit that a research methodology is "a systematic way of sorting and outlining the research problem procedure to resolutions. While a content analysis a technique within the ambits of qualitative research method "a technique used for making valid inferences by interpreting and coding contextual materials through systematically evaluating various texts on a subject line" (Orodho, 2003). The justification of adopting this technique in this article is that the subject lines discussed herein of organizational strategy, environment and decisions are quite common in literature requiring not much of quantitation's of some sort. Therefore, this technique was valuable in helping the researcher decipher the sphere of these factors in an organizational context. In another regard, content analysis allowed the researcher to extensively analyze various literatures and perpetual constructs of organizational strategy, environment and decisions as they're difficult to study via traditional quantitative methods. The objective of the study was to just try explaining how these three factors are important 
to the organization success to formulation and implementation or alignment.

\section{Key Areas for Successful Strategy in an Organization}

It is abundantly clear from here that strategy as we have defined it above is a synthesis of different components worth noting. In section of the article we devise five areas of organizational strategy that are critical to its success from formulation and implementation processes. The first among these areas is the aspect of developing an organizational wide line of business anchored and ascribed on a mission. Hesterly (2006) in his strategic management discourse argued "that defining the organization's business and developing a mission as a basis for establishing what the organization does or doesn't do and where it's headed is the genesis of its strategic maneuvering". The concept of defining the business as you want it now and in the future is a paramount first step in instituting a meaningful direction and developmental path for the organization. Many scholars such as (Fred, 1989, Dess, 1987, Cummings, Stephen, \& Daellenback, 2009) are of the view that whatever the organization seeks to do and to become over the long-term is what constitutes the organization's strategic mission. The strategic mission broadly can be underscored as the forerunner of an excursion into the future; it graphs the future course of the organization. In this vein, (Jack and Robinson, 2000) noted that "since decisions about long-term direction fall squarely upon the shoulders of senior officers, a mission will always reflects the personal vision and thinking of top-level managers concerning the organization.

The second area paramount to the way organizations grow for success through strategy is having clear overall organizational objectives. Time and again organizational objectives are concerned with outcomes; as a result their existence is of great significance to overall delivery and embodiment of a sound strategy (Malhotra et al, 2008). In support of the foregoing, Hoskisson (2001) laid a claim that linked organizational objectives and strategy. He argued that "without clear objectives, organizational strategy in the ambit of strategic management would be a torrid nightmare to undertake". Similarly (Dess, 1987, p: 259-277) posited that organizational objectives specify basic performance targets that are pursued using a strategy. These are necessary because they have an effect on the survival and success of an organization. They are needed at all levels of management, from the corporate level running deep down to the organization's front lines. Organizational objectives does not only convert the direction the organization is taking into specific performance targets, they also guards against drift, aimless activity, confusion over what to accomplish and loss of purpose (Bryson,2004).

On another front, strategic management guru's such as (Mintzberg, 1987, Kotler, 1991, Armstrong, 2002, \& Hesterly, 2006) postulated that organizational objectives are critical to organizational strategy formulation and implementation because they lay down: the market position and competitive standing the organization aims to achieve, annual profitability targets, key financial and operating results to be achieved through the organization's chosen activities, and any other milestone by which strategic success is measured. Because strategy is needed up and down the organization, (Richard, 2002) argued that the objective-setting task of strategic management should involve all managers; each must identify what their area's contribution to the success of strategy will be and then establish concrete, measurable performance targets and indicators thereafter.

The third area of great significance to the success of an organizational strategy is the whole the process of formulating the strategy itself. Hesterly (2006) underscored that this stage denotes the process of coming up with an actual strategic plan. This brings in the critical issue of just how the targeted results are to be accomplished. Cummings, Stephen, and Daellenback (2009) noted that while objectives are "end product", strategy is the "means" of achieving them. Therefore, the task of formulating strategy entails taking into account all of the relevant aspects of the organization's internal and external situations and coming up with a detailed action plan for achieving the targeted short term and long term results. This shows that strategy is a blueprint for all the important entrepreneurial, competitive and functional area actions that are to be taken in pursuing organizational objectives and positioning the organization for sustained success.

According to Dess (1987) General Electric Corporation accentuated the importance of strategy as "a statement of how and what resources are going to be used to take advantage of which opportunities to maximize and which threats to minimize in order to produce a desired result". This gives birth to issues that a formulated strategy must seek to address which are according to Dess (1987) (i) how to respond to changing conditions specifically, what to do about observed shifts in customer needs and emerging industry trends, (ii) which new opportunities to pursue, (iii) how to defend against competitive pressures and other externally imposed threats, (iv) and how to strengthen the mix of the firm's activities by doing more of some things and less of others; (v) how to allocate resources over the organization's various business units, divisions, and functional departments by making decisions that steer capital investment and human resources in behind the chosen strategic plan in ways critical, (vi) putting in place some kind of strategy-supportive guidelines for resource allocation, (vii) how to compete in each one of the industries in which the organization participates and decisions about how to develop customer appeals, through positioning of the organization against rivals, or emphasizing some products and de-emphasize others.

Notwithstanding the above discourse, Armstrong (2002) while recognizing the existence of a strategy for the whole organization as a whole. He distinguished various forms of strategies that can be formulated and 
implemented in and organization. He opined that the "issues of strategy thus go up and down the managerial hierarchy"; strategy is not just something that only top management wrestles with. There are strategies for each line of business the organization is in; strategies at the functional area level such as (manufacturing, marketing, finance, human resources, and so on) within each business; and there are strategies at the operating level (for each department and field unit) to carry out the details of functional area strategy. Optimally, managers closest to the scene of actions help draft, implement and align strategies. They sufficiently coordinate them to produce a unified action plan for the whole organization (Davis and Olson, 2008). The content of each and every strategy in the organization is always a reflection of the long-term direction of the organization in business (Lumpkin 2005). Any need for major new initiatives such as increased competitive aggressiveness, a new diversification move, divestiture of unattractive activities, and actions aimed at keeping the organization in position to enjoy sustained success must be bundled together and be contained in the overall strategy. Lumpkin added that specific entrepreneurial aspects of the strategy formation process should include: searching actively to incorporate serious innovative ways the organization can improve on what it is already doing; identifying new opportunities for the organization to pursue; developing ways to increase the firm's competitive strength and put it in a stronger position to cope with competitive forces; and devising ways to build and maintain a competitive advantage for a good number of years to come.

Hesterly (2006) pointed out that "analysis and operational judgment are important factors that help shape strategy. This means that the right choice of strategy for one organization need not be right for another organization, even those one's in similar business, because situations differ from organization to organization, as well as from time to time. Sturdily positioned firms can do things that weakly positioned ones can't do, and weak firms need to do things that strong ones don't. A good formulated and implemented strategy is one that is right for the organization, considering all of the relevant specifics of its situation (Cummings, Stephen and Daellenback: 2009). The task of formulating strategy thus always requires heavy doses of situational analysis and judgment, with the aim being to achieve "goodness of fit" between strategy and all the relevant aspects of the organization's internal situation and external environment. Indeed, this point to the fact that amongst the special values and priceless contributions of managers is their ability to come up with customized solutions that fit the unique features of an organization's situation (Malhotra, Deepak, Gillian, Ku, Keith and Murnighan 2008).

The fourth aspect or area of organization critical to the success of strategy is the way that particular formulated strategy is implemented. It is not a surprise or strange phenomena to find that an organization's strategy can be well formulated yet poorly implemented or aligned into the organization structure. Richard (2002) opined that "the issue of strategy implementation involves putting the strategy into place and getting individuals and organizational subunits to go all out in executing their part of the strategic plan successfully. By implication this means several managerial challenges, which include: building an organization capable of carrying out the strategic plan; developing strategy-supportive budgets and programs; linking the motivation and reward structure directly to achieving the targeted results; and creating an organizational culture that is in tune with strategy in every successcausing respect. To this respect (Bryson: 2004)) postulated that developing an action agenda for implementing or executing a strategy should involve managers at all levels. This is because deciding on answers to the question "What is required for us to implement our part of the overall strategic plan and how can we best get it done?" and doing the task well means scrutinizing virtually every operating activity of the organization to see what actions can be taken to improve strategy execution and to instill strategy-supportive practices and behavior within employees.

On the one hand (Davis and Olson: 2008) added that the "managerial task of implementing strategy involve a process of moving incrementally and deliberately to create a variety of "fits". Those fits bring an organization's conduct of its internal operations into alignment with strategy. And thus (Davis and Olson) suggests a wide range of fits that demands balancing between them in an organization. The first among these fits is between strategy and internal policies; the second one is between practices and procedures; the third one is between strategy and the internal organizational atmosphere (as determined by the values and beliefs shared by managers and employees; the fourth fit is the philosophy or philosophies and decision-making styles of top managers, and other factors that make up the organization's personality and culture); the fifth one is between strategy and the internal organizational structure; the sixth one is between strategy and organizational skills/technical know-how/operating capabilities.

Notwithstanding the above exposition, (Malhotra, Deepak, Gillian, \& Murnighan: 2008) broad view of strategy execution is one that involves scrutiny of the whole internal organization to order to identify the types of supportive approaches useful and desirable, coupled with certain actions to accomplish them. This calls for the arrangement of different pieces of the implementation plans into a pattern of action that is likely to produce orderly change (from the old to strategy to new strategy) rather than creating a disruption and dissatisfaction in the way things are handled. Malhotra, Deepak, Gillian, \& Murnighan (2008) went further noting that both the sequence of actions and the speed of the implementation process should be treated as key aspects of allying the entire workforce behind strategy accomplishment. 
Last but not the least the fifth important area that adds to the success of organizational strategy in modern times is the act of strategy monitoring and evaluation. Perhaps the opinions of scholars are divided on the assumption that strategy monitoring and evaluation is part and parcel of the cycle to successful organizational strategy. In this article, we posit that strategy monitoring and evaluation is equally significant to achieving success with organizational strategy. As put forward by (Hesterly: 2006) who argued that "though most managers hardly engage in strategy monitoring and evaluation, strategy monitoring evaluation is important in assessing and ascertaining performance of a particular strategic plan and making corrective adjustments". Thompson and Strickland (2003) accentuated that neither strategy formulation nor implementation is a once-and for-all-time task. In both cases, circumstances arises which make corrective adjustments desirable. Strategy may need some panel beating due to the fact that it may not be fitting in well or because changing conditions make fine-tuning, or even major overhaul, necessary. Armstrong (2005) pointed out that "we should note that even a good strategy can be further improved upon, and it requires no great argument to see that changes in industry and competitive conditions". For example, emergence of new opportunities or threats, new executive leadership, a reordering of objectives and the like can all make a change in strategy desirable. Likewise, (Kotler: 1991) argued that with strategy implementation there will be times when one or another aspect of implementation does not go well as planned, making adjustments necessary and this is done when strategy is being monitored or evaluated. The changing internal conditions, as well as experiences with current strategy execution, can drive different or improved implementation approaches (Dess 1987). In this is case, testing out new ideas and learning what works and what doesn't through trial and error is common. Thus, it is always a compulsory task for managers to monitor both how well the chosen strategy is working and how well implementation is proceeding, making corrective adjustments whenever better ways of doing things can be supported (Schilit and Paine, 1987). Therefore, it is imperative to note that the function of strategic management is ongoing, not something to be done once and then neglected.

\section{Points to note:}

First of all, the first three discussed above, when combined offers direction to the organization. The organization's strategic plan is established by these components, and this strategic plan is thus called the directional map. The fourth one is recognized as the most complicated and challenging one because it involves not only deciding on but also undertaking the administrative actions needed to convert the strategic plan into results; indeed, orchestrating the execution of strategy is probably 5 to 10 times more time consuming than is formulating the strategic plan (Hesterly: ibid). The fifth area discussed or the monitoring and evaluation of strategy performance and making corrective adjustments, is both the end and the beginning of the strategic management cycle. The marching of external and internal events guarantees that the time will come for making revisions in the four previous components or areas. In most cases, alterations will be of fine-tuning variety, but it must be mentioned that there are occasions for major overhaul in one or more areas arises sometimes because of substantial external or internal changes in the environment as shall be discussed subsequently.

\section{Understanding the Environment of an Organization (external environment).}

Understanding the environment within which the business operates from is very important for successful running of an organization. Insofar environmental factors are concerned they influence almost every aspect of the organization, be it its nature, its location, the prices of products, the distribution system, or the personnel policies. Hence it is important at this juncture to discuss various constituents of the firms' external environment in particular. This environment consists of various aspects (i) economic aspect, (ii) socio-cultural aspects, (ii) political frameworks, (iv) legal aspects and (v) technological aspect among others like Globalization if we're to discuss it as a standalone factor. Thompson and Strickland (2003) stated that "the success of every business depends on adapting itself to the environment within which it functions". For example, when there is a change in the labor policies of the government, the business has to make the necessary changes to adapt it-self to the new policies; otherwise the long arm of the law will visit it and definitely penalize it.

Child (1999, p: 1-23) argued that "the economic environment of an organization constitutes economic conditions and economic policies of a nation". These refer to a set of economic factors that exert or have great influence on business organizations and their operations. In Zambia like other developing countries in Africa, the following factors underline the economic environment or government economic policies that have serious repercussions on the business houses. Such economic factors includes: fiscal and monitory policies, gross domestic product, per capita income, markets for goods and services, availability of capital, foreign exchange reserve, growth of foreign trade, and strength of capital market among others. These factors as argued by (Child, 1999) have an effect on the pace of economic growth of the individual firms. It being a hair salon in the Compounds of Lusaka city to the booming Trade Kings group of companies is affected by these economic conundrums of the environment. The activities and operations are directly influenced by the economic policies framed by the government from time to time. Fiscal policy and monetary policy are some of the most important economic variables that from time to time the governments tend to change these policies in view of influencing economic 
growth particularly in unstable economies like Zambia. It is for this reason that every business firm has to adapt and function strictly within the economic policy frameworks and respond to the changes adequately.

The social environment of an organization as postulated in (Eissenhardt, 1989. p: 543-776) take in social factors like: customs, traditions, values, beliefs, poverty, literacy, life expectancy rate among others. The social structure and the values that a society cherishes have a considerable influence on the functioning of business firms. In Zambia particularly, during festive seasons there is an increase in the demand for certain product, rice, meat products, new clothes, beer, flowers to mention but a few. Also due to increase in literacy levels local consumers are demanding and becoming more conscious of the quality of the products from the Chinese and Indian producers through social and eco-labeling. The revolution in family composition, more nuclear families with two or single child concepts have come up. This increases the demand for the different types of household goods. It may be noted that the consumption patterns, the dressing and living styles of people belonging to different social structures and culture vary significantly thereof (Richard; 2000).

The political environment as another key component of an organization external environment constitutes of political system of a country. The political systems enact laws and policies and exhibit a peculiar attitude towards the business community and unionism. All these aspects have a bearing on the strategies adopted by the business firms. The political stability or civil unrest of a nation influences business and related activities to a great extent. It sends a signal of strength, confidence to various interest groups and investors (Eissenhardt and Bourgeous, 1998). Furthermore, ideologies within the political parties especially the ruling party also influences the business organization and its operations. To drag this point home, let's consider the issues of Zambianization and privatization that took place in Zambia during the first and third republic respectively that is during Kaunda and Chiluba's epoch. These events had great impacts on firms. A lot of firms were nationalized in by Kaunda and the privatized by Chiluba government of the Movement for Multiparty Democracy (MMD), off course we must mention that this was part and parcel of the gruesome conditions of the World Bank and International Monitoring Funds (IMF) Structural Adjustment Package (SAPs). Another political phenomenon that we can't be sure to negate is trade unionism. It is a well rounded up idea to see that trade unionism activities influence the operation of business enterprises in the world. In countries like Zambia, South Africa among other African countries as the case may be, most labour unions are affiliated to various political parties which must not be the case. Salamon (2000) argued that "industrial unrest in form of strikes; lockouts and unresolved labour disputes etc. adversely affect the business operations". However, in the $21^{\text {st }}$ century trade unions are now showing great maturity and are starting to contribute positively to the success of the business organization and its operations through workers participation in management.

Coming to the legal aspect of an organizational environment, it comprises of set of laws and country regulations, across the board or within the competitive industry particular firms operates from. For example, mining and exploration, production, tourism, education to mention but a few. These laws and regulations have a significant influence on the business organizations and their operations. According to (Hoskison; 2001) every business organization has to obey, and work within the framework of the law. The important legislations that concern business enterprises in Zambia include: The factories Act, 1992; Health and Safe Act, Minimum Wages and Conditions of Employment Act Cap 269: Industrial and Labour Relations Act Cap 268, to mention but a few. Besides, the above legislations, there are international standards and the Constitution and Judicial decisions of any government which are part and parcel of the legal environment that organizations need to be governed by every time.

Besides the economic, social, political and legal aspects of the external environment, we also have the technological aspect of the environment which includes: the methods, techniques and approaches adopted for production of goods and services and its distribution. Hoskison (2001) posits that "varying technological environments of different countries affect the designing, production and distribution of products and services". In the modern competitive age, the pace of technological changes is very fast. Hence, in order to survive and grow in the market, a business has to adopt the technological changes from time to time. Engendering into scientific research for improvement and innovation in products and services should be regular activity in big or small industrial organizations. Nowadays no firm can afford to persist with the outdated technologies. This for example had devastating effects on the front of local firms in Zambia particularly the Public Enterprises. They failed prey to advancement in technology in the early periods of the turnaround in technological advancements. Public enterprises like Zambia Postal Services with its core business in postal services could not stand to the arrival of cell phones with embedded services like text messages, email services, fax and general direct dial or communication. The firm upto now hasn't strove to become or emulates the likes of DHL, FedEx or Royal mail among others doing well in the business. It is becoming a lot more of a white elephant with serious scams of organizational unrest and it is tangled in deep political conundrums.

Lastly organization success is also hampered by challenges and opportunities present in the natural environment. These include geographical and ecological factors that influence the business operations. These factors according to (Hesterly; ibid) include the availability of "natural resources, weather and climatic condition, 
location aspect, topographical factors", etc. A business house is influenced by the nature of natural environment, for example, sugar factories are set up only at those places where sugarcane can be grown. It is always considered better to establish manufacturing unit near the sources of input. Further, government's policies to maintain ecological balance, conservation of natural resources etc. put additional responsibility on the business sector.

\section{Decision Making and Types of Decisions in Organizations}

In this subsequent chapter of this article, we are going to discuss organizational decision making and the types of decisions made in various organization in line with strategic management auspices. To begin with (Schilit and Paine 2004, p: 161-187) posits that "changes in the organization's environment, the ups and downs are constant drivers of strategy adjustments". These judgments and adjustments are what we call decisions; therefore decision making is at the heart of modern organizational management. This process involves taking a range of decisions as shall be explained below.

According to (Schilit and Paine, 2004) there are generally a number of decisions that managers and nonmanagement personnel make in organizations, either at household level, church level, business level or at personal level. Two of such decisions are programmed and non-programmed ones. The programmed decisions are concerned with the problems of repetitive nature or routine type of matters (Ruso and Schoemaker, 2002). A standard procedure is followed for tackling such problems. These decisions are taken generally by lower level managers. Decisions of this type may pertain to purchase of raw material, granting leave to an employee and supply of goods and implements to the employees. Often referred as routine decisions, programmed decisions relate to the general functioning of the organization or planned activities. They do not require much evaluation and analysis and can be taken quickly. Sufficient discretion of authority is delegated to lower ranks to take these decisions within the broad policy structure of the organization (Murnighan and Mowen, 2002).

Whereas non-programmed decisions relate to difficult situations for which there is no easy solutions? These matters are very important for the organization, for example, opening of a new branch of the organization or a large number of employees absenting from the organization or introducing new product in the market (Burgelman, 2000, p: 61-70). These are the decisions which are normally taken at the higher level of management in any organization. Non-programmed decisions or strategic decisions are choices pertaining to objectives, goals and other important policy matters of an organization. These decisions usually involve huge investments or funds (Luchman, 1998, p: 89-99). These are non-repetitive in nature and are taken after careful analysis and evaluation of many alternatives.

The other types of decisions that are made in organizations are the tactical (policy) and operational decisions. According to (Schilit, 2004) these "decisions pertain to various policy and operational matters of the organization". These are taken by the top management and have long term impact on the functioning of the concern. For example, decisions regarding location of plant, volume of production and channels of distribution among others. Operating decisions relate to day-to-day functioning or operations of a business. Middle and lower level managers take these decisions. For example decisions concerning payment of bonus to employees are a policy decision. On the other hand if bonus is to be given to the employees, calculation of bonus in respect of each employee is an operating decision (Rajogopalan, Rasheed and Datta, 1993, p: 349-364).

Beside we have also the organizational and personal decisions as part and parcel of the functioning of the organization: Vroom and Yutton (1993) argued that "when an individual takes a decision as an executive in the official capacity, it is known as organizational decision". However, if a decision is made by the executive in the personal capacity (thereby affecting his/her personal life), it is known as personal decision. Sometimes these decisions may affect the functioning of the organization since individuals employees are part and parcel of the organizations. For example, if an executive leaves the organization, it may affect the organization. The authority of taking organizational decisions may be delegated, whereas personal decisions are not delegated.

Similarly, there are individual and group decisions, when the decision is taken by a single individual, it is known as individual decision. Usually routine type decisions are taken by individual employees within the broad policy framework of the organization (Eissenhardt and Zbarack, 1992, p: 17-37). Whereas group decisions are decisions taken by a group of individuals constituted in the form of a standing committee or team. Generally very important and pertinent matters for the organization are referred to this committee or team (Shull and Cummings, 1970). The main aim in taking group decisions is to involve a maximum number of individuals in the process of decision- making and increase the viability of the decision being made.

\section{Conclusion}

This article delved to discuss platforms or areas were the success of the organizational strategy can be made or be broken. The organizational environment particularly the external environment and the kinds of decisions made in organizations were discussed in greater heights. It was postulated that strategy is set of decisions or a plan and actions taken to provide a competitively superior fit between the organization and its environment so as to achieve organizational goal and objectives. Thus managers need to determine how a firm is to compete so that it can obtain 
an advantage that is sustainable over a lengthy period of time over its rivals. Every organization exists to grow and survival in a constantly changing and competitive setting. To do so, it must respond and adjust to the social, economic, technological and political environmental changes that occur. The environments of organizations according to (Bryson, 2004) have become not only increasingly uncertain in recent years but also more tightly interconnected; thus changes anywhere in the system reverberate unpredictably, and often chaotically and dangerously throughout the environment. This increased uncertainty and interconnectedness requires responses from the organizations in form of decisions which are tactical, routinely, strategic, organizational, programmed and un-programmed in nature.

\section{References}

Armstrong, M (2002) Strategic HRM: The route to improved business performance, Chartered Institute of Personnel and Development, London

Baxter, P., \& Jack, S. (2008). The Qualitative Report Qualitative Case Study Methodology: Study Design and Implementation for Novice Researchers. The Qualitative Reportualitative Report, 13(2), 544559.https://doi.org/citeulike-article-id:6670384

Bhide, A. (1994) how entrepreneurs craft strategies that work. Harvard Business Review.72 (2), 150-161.

Bryson John, M. (2004) Strategic Planning for Public and Nonprofit Organizations; A guide to strengthening and sustaining Organizational achievements, San Francisco, Jossey-Bass

Burgelman, R.A. (1989) Strategy is Destiny (The Free Press, New York: 2000).Camp, R.C. Benchmarking: the search for industry best practices that lead to superior performance (ASQC Quality Press, Milwaukee

Child, J. (1972) Organizational structure, environment, and performance: The role of strategic choice, Sociology, $6,1-22$

Cummings, Stephen, and Daellenback. (2009) "A Guide to the Future of Strategy? The History of Long Range Planning” Long Range Planning: 234-263

Davis, A, and E.M. Olson (2008) "Critical Competitive Strategy Issues Every Entrepreneur Should Consider Before Going into Business.” Business Horizons 51, no. 3 p. 211.

Dess. G.G. (1987) Consensus on strategy formulation and organizational performance: Competitors in a fragmented industry. Strategic Management Journal, 8, 259-277.

Eisenhardt, K. M. (1989) Making fast strategic decisions in high-velocity environments. Academy of Management Journal, 12, 543-576.

Eisenhardt, K. M. \& Bourgeois, L.J. (1988) Politics of strategic decision making in high-velocity environments: Toward a midrange theory. Academy of Management Journal, 33, 737-770.

Eisenhardt, K.M. \& Zbaracki, M.J. (1992) Strategic decision making. Strategic Management Journal, 13, $17-37$.

Fred R. David, "How Companies Define Their Mission,” Long Range Planning 22, no. 1 (February 1989): 91.

Hesterly, W.S. (2006) Strategic Management and Competitive Advantage: Concepts and Cases, Pearson Prentice Hall

Hoskisson, R.E. (2001) Strategic Management: Competitiveness and Globalization, South-Western

Jack .R and R. Robinson (2000) Strategic Management, 7th ed. (New York: McGraw-Hill, p; 8

Kotler, P. (1991) Marketing Management: Analysis Planning, Implementation, Northwestern University, U.S.A, Prentice-Hall International, Inc.

Luehrman, T.A (1998) "Strategy as a portfolio of real options, Harvard Business Review, 76(5), 89-99

Lumpkin, D. (2005) Strategic Management Theory: An Integrated Approach, Houghton Mifflin

Malhotra, Deepak, Gillian, Ku, Keith and Murnighan (2008) "When Winning Is Everything." Harvard Business Review 78

Mintzberg, H T (1991) Crafting strategy, Harvard Business Review, pp. 66-74

Murnighan, J.K, \& Mowen, J.C. (2002) The Art of High-Stakes Decision-Making, New York: John Wiley \& Sons. Orodho, A.J (2003) Essentials of Education and Social Science Research Methods, Nairobi, Masola Publishers

Rajagopalan, N., Rasheed, A.M., \& Datta, D.K. (1993) Strategic decision processes: Critical review and future directions. Journal of Management, 19, 349-364.

Richard A. (2002), Ten Keys to Successful Strategic Planning for Nonprofit and Foundation Leaders, Briefing Paper, TCC Group

Russo, J.E. \& Schoemaker, P.J.H. (2002) Winning Decisions. New York: Doubleday.

Salamon, M. (2000) Industrial relations theory and practice, 4th edition, Pearson education limited, England

Schilit, W.K. \& Paine, F.T. (1987) An examination of the underlying dynamics of strategic decisions subject to upward influence activity, Journal of Management Studies 24, 161-187.

Shull, F, Delbecq, A, \& Cummings, L. (1970) Organizational decision making, New York: McGraw Hill

Thompson, A. and Strickland A. J, (2003) Strategic Management, Concepts and Cases Thirteenth Edition, McGraw Hill Irwin.

Vroom, V.H \& Yetton, P.W. (1973) Leadership and decision making, Pittsburgh, University of Pittsburgh Press 